\title{
Strategi Personal Branding Alexander Thian Sebagai Storygrapher Melalui \#LetMeTellYouAStory
}

\author{
Mufida Nursufyana \& Itca Istia Wahyuni \\ Program Studi Ilmu Komunikasi, Fakultas Komunikasi dan Bisnis, Universitas Telkom \\ Jalan Telekomunikasi No. 01, Dayeuhkolot Bandung Jawa Barat 40257, Indonesia
}

E-mail: sufyanamufi@gmail.com

Naskah diterima 12 Oktober 2019, Revisi 23 Januari 2019, Terbit 20 April 2019

DOI: http://dx.doi.org/10.21107/pmt.v12i1.5174

\begin{abstract}
ABSTRAK
Dalam sosial media Instagram, diketahui bahwa konten mengenai traveling lebih diminati oleh masyarakat saat ini. Dampaknya, banyak pengguna Instagram yang bersaing untuk menyajikan konten traveling dengan ciri khas masing-masing. Untuk akhirnya dapat memenangkan persaingan, maka diperlukanlah sebuah strategi untuk mem-branding diri sendiri. Penelitian ini membahas mengenai strategi personal branding yang dimiliki oleh akun Instagram @amrazing sebagai storygrapher. Metode penelitian yang digunakan adalah deskriptif kualitatif berdasarkan hasil wawancara dengan informan yang telah terpilih. Berdasarkan hasil penelitian, diketahui dalam tahap perumusan strategi, Alex ingin mengembangkan personal branding dari seorang story-teller menjadi story-grapher dengan menggunakan hashtag \#LetMeTellYouAStory dalam caption. Lalu dalam implementasi strategi, Alex menyesuaikan penggunaan hashtag tersebut pada beberapa postingan terpilih saja dengan memfokuskan pada elemen spesialisasi, kepribadian, konsisten dengan positioning, kepemimpinan, nama baik, dan keteguhan. Pada tahap evaluasi melalui alat pengukur tak langsung diketahui bahwa followers Alex memiliki persepsi yang serupa dengan apa yang diupayakan Alex dalam tahapan implementasi strategi personal branding-nya.
\end{abstract}

Kata Kunci: Personal Branding, Strategi, Storygrapher, Alexander Thian

\section{PENDAHULUAN}

Fenomena menjamurnya penggunaan media sosial di Indonesia membuat masyarakat semakin aktif untuk melakukan aktivitas mereka di dunia maya. Salah satu media sosial yang banyak digunakan oleh masyarakat Indonesia adalah Instagram. Tercatat dalam sehari, pengguna Instagram dari Indonesia mampu menghasilkan konten instagram story dua kali lebih banyak dibandingkan dengan rata-rata global. (sumber liputan6.com diakses pada tanggal 13 Agustus 2018 pukul 11.46).

Dari sekian banyak pengguna Instagram di Indonesia serta banyaknya konten yang disebarkan, muncul beberapa konten yang disebut sebagai konten yang paling digemari oleh masyarakat. Penilaian dari konten yang paling digemari ini berdasarkan banyaknya pengguna yang membagikan, mencari, dan menyimpan konten tersebut. Berdasarkan data yang diperoleh penulis, konten mengenai travel menempati posisi pertama sebagai konten yang paling banyak di-upload dengan 46,7\%. Angka tersebut unggul dari 31,3\% konten tentang makanan dan konten restoran yang memperoleh angka 18,7\%. (sumber: https://dailysocial.id/post diakses pada tanggal 16 Agustus 2018 pukul 14.07).

Komunikasi merupakan rangkaian proses pengalihan informasi dari satu pihak kepada pihak yang lain secara efektif sehingga pesan yang dimaksud dapat dipahami. Tujuan manusia berkomunikasl yaitu untuk membagikan pengetahuan dan pengalaman kepada orang lain. Sedangkan menurut Effendy (2003) menyimpulkan bahwa fungsi komunikasi dapat disederhanakan menjadi empat fungsi : (1) menyampaikan informasi (to inform); (2) mendidik (to educate); (3) menghibur (to entertain), dan (4) mempengaruhi (to influence). 
Menurut Mulyana (2005) komunikasi adalah proses dimana suatu ide dialihkan dari sumber kepada satu penerima atau lebih, dengan maksud untuk mengubah tingkah laku mereka. Tujuan akhir dari proses komunikasi adalah perubahan tingkah laku dari penerima pesan yang diakibatkan oleh pesan yang diterima.

American Marketing Association (AMA) mendefinisikan brand (merek) sebagai sebuah nama, istilah, tanda, lambang, desain, rancangan, atau kombinasi hal hal tersebut, yang dimaksudkan untuk mengidentifikasi barang atau jasa dari seseorang penjual atau sekelompok penjual dan untuk membedakannya dari produk atau jasa dari para pesaing (Kotler \& Keller, 2009).

Branding menurut Peter Montoya merupakan sebuah proses menciptakan identitas yang dikaitkan dengan persepsi, emosi, dan perasaan tertentu terhadap identitas tersebut (Rampersad 2008). Tanpa sebuah merek yang kuat, pemasaran tidaklah efektif. Oleh karena itu branding sangat dibutuhkan demi menciptakan sebuah merek yang kuat.

Personal branding saat ini diperlukan untuk dimiliki setiap orang. Tidak terbatas kepada tokoh-tokoh penting saja. Haroen (2014) mengungkapkan personal branding adalah proses membentuk persepsi masyarakat terhadap aspek-aspek yang dimiliki oleh seseorang, diantaranya adalah kepribadian, kemampuan, atau nilai-nilai, dan bagaimana semua itu menimbulkan perspektif positif dari masyarakat. McNally \& Speak (2002) mengungkapkan tiga buah komponen utama pembentuk merek pribadi atau personal branding yakni:

a. Khas : membangun personal branding yang kuat dimulai ketika Anda bertekad untuk bertindak dengan dasar kepercayaan tersebut. Khas atau unik yang dimaksud adalah memahami dan melakukan tindakan berdasarkan nilainilai yang merupakan prinsip dalam kehidupan sehari-hari.

b. Relevan : membangun relevansi dimulai dari memperhatikan dan menentukan apa kebutuhan dan minat orang kebanyakan, baru kemudian menghubungkan kebutuhan tersebut dengan kekuatan dan kemampuan Anda sendiri.

c. Konsisten : Komponen ketiga dalam membangun personal branding yang kuat adalah konsistensi, atau dengan kata lain melakukan hal-hal yang khas dan relevan, kemudian melakukannya lagi, lagi, dan lagi.

Strategi komunikasi berhubungan dengan penggunaan sumber daya komunikasi untuk mencapai suatu tujuan tertentu. Middleton (1980) menjelaskan definisi dari strategi pada komunikasi adalah kombinasi terbaik dari semua elemen komunikasi mulai dari komunikator, pesan, saluran (media), penerima sampai pada pengaruh (efek) yang dirancang untuk mencapai tujuan komunikasi yang optimal. (Cangara, 2014).

New media digunakan sebagai istilah yang diartikan sebagai teknologi komunikasi baru yang menghasilkan efek budaya yang luas, sulit diprediksi dan mengganggu serta mengubah dinamika hubungan manusia (Sanar, 2014). Denis McQuail dalam buku Teori Komunikasi Massa menyebutkan bahwa new media memiliki beberapa ciri khusus yakni, adanya saling ketergantungan antara akses terhadap individu sebagai penerima atau pengirim pesan, memiliki banyak kegunaan dan sifatnya terbuka.

Sesuai dengan pernyataan dari buku The Instagram Handbook karangan Kjell $\mathrm{H}$. Landsverk dimana disebutkan bahwa Instagram merupakan jaringan sosial yang terkenal dan digunakan untuk mengunggah foto. Selain mengunggah foto, pengguna juga dapat mengedit tampilan pada foto dan membagikan foto tersebut dengan pengguna lain. (Landverk, 2014).

Hashtag atau tagar umumnya digunakan untuk mengelompokkan suatu pesan yang serupa dalam media sosial. Dalam penelitian Nofi (2017), hashtag kemudian digunakan dalam jaringan IRC (Internet Relay Chat) untuk mengelompokkan label dan topik. Hashtag juga digunakan untuk menandai pesan individu yang relevan dengan kelompok atau topik tertentu.

Salah satu pengguna Instagram yang memiliki konten mengenai traveling adalah 
@amrazing atau yang memiliki nama Alexander Thian. Nama akunnya seringkali masuk ke dalam top list akun dengan konten traveling yang wajib untuk di-follow berdasarkan beberapa situs online seperti pegipegi.com dan kompasiana.com. Selain nama Alex, dalam list yang diterbitkan juga memiliki nama-nama akun lain yang serupa dengan Alex. Agar personal branding dirinya tetap terlihat berbeda dari yang lain, Alex memilih untuk memperhatikan konten-konten yang dibagikan. Dalam bio Instagram miliknya, Alex menyebut dirinya sebagai story-grapher, perpaduan kata story-teller dan fotografer.

Hal ini didasarkan bahwa dalam setiap postingannya, Alex selalu bercerita dalam caption-nya mengenai banyak hal, baik itu pengalaman saat traveling, pemikirannya akan suatu permasalahan, atau tentang cerita hidupnya. Dalam memposting sesuatu, Alex juga sering menambahkan hashtag \#LetMeTellYouAStory dalam caption postingannya.

Selain dalam postingan Instagram, Alex juga menggunakan hashtag tersebut diluar dari ranah media sosial, yakni saat event solo fotografi yang diadakan saat awal tahun 2018. Menggunakan hashtag \#LetMeTellYouAStory dan istilah storygrapher, Alex membangun personal branding-nya sebagai seorang pencerita yang juga berbagi foto-foto yang indah. Berdasarkan pemaparan tersebut, penulis tertarik untuk meneliti mengenai tahapantahapan dalam kegiatan personal branding Alex dengan positioning dirinya sebagai seorang story-grapher dalam pandangan audience dengan penelitian berjudul, "Strategi Personal Branding Alexander Thian sebagai Storygrapher Melalui Hashtag \#LetMeTellYouAStory".

\section{METODOLOGI}

Dalam penelitian ini, penulis menggunakan paradigma konstruktivis untuk mengetahui strategi personal branding Alexander Thian. Paradigma ini memandang ilmu sosial sebagai analisis sistematis terhadap socially meaningful action melalui pengamatan langsung dan terperinci terhadap pelaku sosial yang bersangkutan dalam menciptakan dan memelihara/mengelola dunia sosial mereka. (Hidayat, 2003). Selain itu, penulis menggunakan metode kualitatif deskriptif. Metode penelitian deskriptif adalah penelitian yang dilakukan untuk melukiskan, menggambarkan, atau memaparkan, keadaan suatu objek (realitas atau fenomena) secara apa adanya, sesuai dengan situasi, kondisi yang sebenarnya (Ibrahim, 2015). Data yang diperoleh dalam penelitian ini berasal dari wawancara mendalam dari informan yang telah ditentukan dan sumber data yang tidak langsung seperti postingan Instagram @amrazing.

\section{HASIL PENELITIAN \\ Perumusan Strategi Personal Branding}

Alex memiliki visi untuk mengembangkan personal branding yang semula adalah story-teller menjadi sebuah hal yang baru yang sesuai dengan apa yang disukai oleh masyarakat saat ini. Untuk itulah Alex memiliki misi untuk belajar mengenai fotografi, editing video dan semacamnya. Hal ini dilakukan untuk mengembangkan personal branding yang semula adalah story-teller menjadi story teller dengan visual-teller, dengan memadukan foto dan caption dalam setiap postingan.

\section{Identifikasi Kebutuhan Stakeholder}

Stakeholder yang paling diperhatikan oleh Alex tidak lain adalah followers-nya sendiri. Alex memperhatikan insight dari followers Instagram miliknya yang berasal dari usia 25-34 tahun dengan 70\% berjenis kelamin perempuan. Sebagai seorang influencer, Alex memperhatikan setiap postingannya agar tetap sesuai dengan keinginannya untuk tidak menjadi sebuah iklan baris sehingga followers-nya tetap tidak keberatan untuk terus memfollow dirinya.

\section{Menetapkan Brand Positioning Statement}

Alex menggunakan istilah storygrapher hashtag \#LetMeTellYouAStory sebagai positioning Alex dalam personal branding miliknya. Baik storygrapher dan 
hashtag \#LetMeTellYouAStory samasama menunjukkan keunggulan Alex dalam fotografi dan story-telling.

\section{Implementasi Strategi Personal Branding}

Alex menunjukkan spesialisasi yang dimiliki melalui ability sebagai seorang penulis atau story-telling dan fotografer. Spesialisasi Alex dalam keduanya dinilai cukup kuat oleh informan yang berasal dari ahli personal branding untuk memudahkan Alex mendapatkan engagement yang cepat.

Sesuai dengan aspek-aspek dalam kepribadian yang disebutkan oleh Montoya (2002), personal branding Alex sebagai story-grapher dengan hashtag \#LetMeTellYouAStory baik dalam event solo fotografi dan instagram, memiliki aspek reliability, authenticity dan fallibility. $\mathrm{Hal}$ ini ditunjukkan melalui penulisan caption yang selalu apa adanya dan dapat menghadirkan emosi baik dalam postingan instagram atau saat event solo fotografi.

Untuk menjaga integritas yang dimiliki, Alex menggunakan \#LetMeTellYouAStory hanya pada saat-saat ingin bercerita dan untuk menjaga agar tetap konsisten, Alex menetapkan untuk memposting 2-3 kali postingan setiap minggunya yang menggunakan hashtag tersebut. Dalam kerjasama dengan brand atau ketika menyelenggarakan event solo fotografi, Alex tetap konsisten dengan positioning sebagai story-grapher dengan dua keunggulan yang ditunjukkan yakni fotografi dan story-telling untuk menjaga integritasnya.

Dengan konsisten untuk menetapkan sebuah standar dari penggunaan hashtag \#LetMeTellYouAStory, Alex mendapatkan pengakuan untuk kredibilitasnya karena selalu menyajikan postingan foto dan caption yang dinilai baik oleh ahli personal branding yang juga mengikuti Alex di instagram.

Dalam setiap penulisan caption, Alex berusaha menyisipkan pemikirannya mengenai berbagai hal, baik itu dari pengalamannya sendiri atau pandangannya akan suatu keadaan di masyarakat. Penilaian dari implementasi elemen ini terlihat dari respon yang diberikan oleh followers melalui kolom komentar dan fitur direct message.

Alex tidak akan mengubah hashtag \#LetMeTellYouAStory dalam caption postingan instagram. Alex juga dinilai telah melakukan inovasi yang baik dengan membawa hashtag \#LetMeTellYouAStory sebagai judul dari event solo fotografi. Followers Alex dapat membedakan Alex dari travel influencer lainnya berdasarkan tulisan Alex dalam caption yang dapat membahas berbagai macam hal. Followers tersebut juga mengakui memahami makna dari istilah storygrapher dan memiliki kesamaan dengan keunggulan Alex dalam fotografi dan story- telling.

Kepribadian Alex dinilai sebagai pribadi yang ramah karena sering membalas komentar atau direct message dari followers-nya. Selain itu, sebagai influencer, Alex dikenal jujur karena benar-benar memilih mana produk yang bisa Alex ceritakan dengan positioningnya sebagai story grapher.

Followers Alex lebih memperhatikan kualitas dari konten-konten postingan Alex yang diberi hashtag \#LetMeTellYouAStory dibandingkan dengan kuantitas mereka menemukan hashtag tersebut digunakan oleh Alex setiap harinya. Alex dinilai telah mampu menunjukkan kredibilitasnya sebagai seorang story-grapher karena mampu mempengaruhi pihak lainnya sesuai dengan arahannya, seperti mengikuti giveaway, atau mem-follow akun lain yang direkomendasikan oleh Alex. Sejak mem-follow Alex di media sosial Instagram, followers Alex juga mendapatkan manfaat dari postinganpostingan Alex. Manfaat tersebut antara lain mengubah pola pikir dan membantu memberikan gambaran mengenai suatu destinasi. 
Followers Alex menyetujui bahwa hashtag \#LetMeTellYouAStory dalam Instagram tidak perlu untuk diganti dengan hashtag lain lagi dan telah mengetahui bahwa hashtag \#LetMeTellYouAStory digunakan juga dalam event folo fotografi Alex yang memiliki merchandise berupa totebag dan kaos dengan tulisan hashtag serupa.

\section{KESIMPULAN}

Berdasarkan data yang telah penulis kumpulkan, diketahui bahwa personal branding Alexander Thian sebagai storygrapher memiliki sebuah strategi yang terdiri dari beberapa tahapan. Tahapan-tahapan tersebut saling terhubung untuk akhirnya menjadikan Alex berhasil dalam mem-branding dirinya sebagai storygrapher dengan hashtag \#LetMeTellYouAStory. Dalam tahapan pertama yakni perumusan strategi, Alex pertama-tama menetapkan cita-cita personal branding-nya kemudian mengenali kebutuhan dari stakeholder yang dimiliki. Kemudian Alex menetapkan brand positioning statement sebagai storygrapher dengan menggunakan hashtag \#LetMeTellYouAStory yang dinilai telah menggambarkan keunggulan Alex dalam bidang storytelling dan fotorgrafer.

Dalam tahap implementasi strategi, Alex tidak hanya menggunakan positioning sebagai storygrapher dan hashtag \#LetMeTellYouAStory dalam media sosial instagram saja, tetapi juga dalam event solo fotografi Alex. Melalui kedua channel tersebut, Alex tetap mempertahankan keunggulannya dan mampu untuk menghadirkan emosi yang berbeda dari foto yang sama yang ditampilkan dalam event dan yang diposting melalui akun instagram @amrazing. Selain itu, Alex juga dianggap memiliki kredibilitas dan keunikan karena mampu untuk tidak sekedar menyajikan foto yang bagus, tetapi juga dengan caption yang menarik juga.

Evaluasi strategi personal branding Alex sebagai storygrapher didasarkan dari komentar-komentar atau masukan yang diperoleh dari followers instagram Alex. Hasilnya, followers Alex telah mengasosiasikan \#LetMeTellYouAStory dengan akun instagram Alex dan memahami makna dari istilah storygrapher yang dijadikan Alex sebagai positioning. Followers Alex juga bertahan untuk terus mem-follow Alex karena mendapatkan manfaat dari postingan-postingan Alex, baik itu saran destinasi wisata, atau cerita yang Alex sampaikan dalam caption postingannya.

\section{DAFTAR PUSTAKA}

Haroen, D. 2014. Personal branding Kunci Kesuksesan di Dunia Politik. Jakarta: PT Gramedia Pustaka Utama

Hunger, D \& Wheelen, T.L. 2003. Manajemen Strategis. Andi. Yogyakarta.

Kotler, P \& Keller, J. 2009. Manajemen Pemasaran. Jilid I. Edisi ke 13. Jakarta: Erlangga

McNally, D., \& Speak, K. D. 2002. Be Your Own Brand. San Fransisco: Berret Koehler Publisher

Mulyana, D. 2005. Pengantar IImu Komunikasi. Bandung. PT Remaja Rosdakarya

Rampersad, K. 2008. Authentic Personal Branding. North Carolina: Age Publishing

Uchjana, E.O. 2003. Ilmu, Teori dan Filsafat Komunikasi. Bandung: Citra Aditya Bakti. 